ORIGINAL PAPER

\author{
Eur. J. Histochem \\ 45: 31-38, 200 \\ (C) Luigi Ponzio e figlio - Editori in Pavia
}

\title{
Spatial expression of DNA topoisomerase I genes during cell proliferation in Daucus carota
}

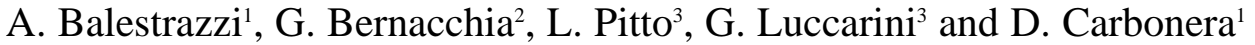

'Department of Genetics and Microbiology "A. Buzzati-Traverso", University of Pavia, Via Abbiategrasso 207, 27100 Pavia, Italy; ${ }^{2}$ Department of Biology, University of Ferrara, Via Borsari 46, 44100 Ferrara, Italy and ${ }^{3}$ Istituto di Mutagenesi e Differenziamento, C. N. R., via Svezia 2/105, 6100 Pisa, Italy.

Accepted: $15 / 10 / 00$

Key words: DNA topoisomerase I, in situ RNA hybridization, cell proliferation, somatic embryo, carrot

\section{SUMMARY}

The spatial expression of carrot (Daucus carota L.) top1 genes encoding the two isoforms of the enzyme DNA topoisomerase I (EC 5.99.1.2) was investigated. In situ hybridization analysis performed with a probe recognizing both topl transcripts provided evidence that in explanted hypocotyls induced to proliferate in vitro by the addition of the growth regulator 2,4-dichlorophenoxyacetic acid (2,4-D), the mRNA accumulation parallels the proliferation of provascular cells of the stelar cylinder. During somatic embryogenesis, the histological distribution of topl transcripts was strongly evident at the stage of torpedo-shaped embryos, but gene expression was not only restricted to meristematic regions. When the spatial localization was extended to carrot vegetative apices and the investigation was carried out with specific probes for topl $\alpha$ and top $1 \beta$, both transcripts preferentially accumulated in tissues having mitotic activity.

\section{INTRODUCTION}

In plants, the understanding of molecular events that regulate cell division is relevant for studies concerning development. Many of the genes that in animals have been described to regulate cell transition to S- or to M-phase have been found also in plants and it is likely that the cell cycle machinery is characterized by the presence of similar components in all eukaryotic cells (Hirt and Heberle-Bors, 1994). Nevertheless, due to the different life strategies characterizing animals and plants, it is unlikely to imagine that the cell cycle machine might be regulated by identical environmental and endogenous signals (Steeves and Sussex, 1989).

DNA topoisomerase I (EC 5.99.1.2) is an ubiquitous enzyme involved in basic processes such as DNA replication, recombination and transcription (Wang, 1996). Due to its ability to transiently break and rejoin phosphodiester bonds, topoisomerase I controls the topological state of DNA molecules. In eukaryotes, the nuclear type I protein forms covalent but transient 3'-phosphotyrosine intermediates with DNA molecules, then relieving the torsional restraints of DNA.

Among the possible roles played in cell metabolism, the involvement of topoisomerase I in the regulation of gene transcription appears to be of great interest. It has been suggested that the 
enzyme could be involved in the activation of chromatin by inducing topological modifications. Moreover, a recent study has demonstrated the involvement of the type I enzyme in the activation and repression of the basal transcription as component of the TFIID complex (Merino et al., 1993).

The expression of topl gene, which is tightly regulated at the transcriptional level, is both constitutive and induced by stimuli among which those inducing cell proliferation, as demonstrated in several mammalian systems: in cultured fibroblasts upon stimulation with serum (Romig and Richter, 1990a) or with a phorbol ester (Hwong et al. 1989) and following adenovirus infection (Romig and Richter, 1990b), in lymphocytes induced to proliferate with phytohemagglutinin (Hwong et al., 1993), in liver cells after partial hepatectomy (Kelly et al., 1983).

Recently, additional activities have been demonstrated for mammalian topoisomerase I: a specific kinase activity, phosphorylating RNA splicing factors (Rossi et al., 1996), and a ribonuclease activity (Sekiguchi et al., 1997). These newly discovered roles suggest the presence of additional functions besides the well known involvement in DNA replication.

The nuclear localization of topoisomerase I is associated with the presence of several NLS (nuclear localization signals) consensus sequences located in the $\mathrm{NH}_{2}$-terminal domain of the protein (Alsner et al., 1992). In proliferating cells the enzyme has been demonstrated to have essentially a nucleolar distribution, even if the localization pattern seems to depend also on cell type (Meyer et al., 1997). Recently, it has been demonstrated that leucine-starved CEM cells are characterized by a perinuclear redistribution of topoisomerase I (Baker et al., 1995). This localization is also observed in response to specific topoisomerase I inhibitors; however, the mechanism leading to this event is still unknown (Buckwalter et al., 1996). Differently from animal systems, information about tissue distribution and subcellular localization of this enzyme are completely missing in the plant kingdom.

In a previous paper, we provided evidence for the presence of two distinct DNA topoisomerases I (designated $\alpha$ and $\beta$ ) in carrot nuclei (Balestrazzi et al., 2000). Moreover, we showed that both top $1 \beta$ and top $1 \alpha$ genes are expressed in cycling cultured cells; however, the top $1 \beta$ transcript represents the most abundant species in proliferating cells, where the ratio between the $\beta$ and $\alpha$ mRNA levels was calculated to be 2.5 .

As a start point for future investigations, we report the analyses of the spatial distribution of both top 1 transcripts in two systems offering the opportunity of correlating the induction of cell division to the time of mRNA accumulation. Finally, using two distinct probes recognizing specifically top $1 \alpha$ or top $1 \beta$ transcripts, we compare their spatial distribution in the vegetative apices from carrot plants.

\section{MATERIALS AND METHODS}

\section{Plant materials}

Embryogenic cell lines of Daucus carota (cv. Lunga di Amsterdam) were initiated as described by deVries et al. (1988). Carrot cell suspensions were subcultured by diluting cells with B5 fresh medium (1:10) every 10 d (Cella et al. 1987). Somatic embryogenesis was started by diluting and transferring embryogenic cultured cells to B5 medium devoid of 2,4-D, essentially as described by Giuliano et al. (1983). Carrot seeds were sterilized essentially as described by Balestrazzi et al. (1991). Seeds were induced to germinate in sterilized soil and plantlets maintained in a growth chamber at $25^{\circ} \mathrm{C}$ with a $16 / 8$ day/night cycle.

In situ ${ }^{35}$ S-labelled RNA hybridization analysis In situ hybridization analyses with paraffinembedded tissue sections from carrot hypocotyls and embryos were essentially carried out as described by Smith et al. (1987). The ${ }^{35} \mathrm{~S}$-labelled sense and antisense RNA probes for topl RNA were derived from the $1.5 \mathrm{~kb}$ EcoRI-SpeI fragment from pTop28 clone (Balestrazzi et al., 1996).

\section{In situ digoxigenin-labelled RNA hybridization} analysis

In situ hybridizations were performed on paraffin-embedded longitudinal sections of apical meristems of 50-days old carrot plants in accordance to the method described by Coen et al. (1990). Digoxigenin-labelled RNA probes corresponded to restriction fragments containing the 5' region specific for topl $\alpha$ and topl $\beta$ cDNAs 
(Balestrazzi et al., 2000) were added to the hybridization solution at $600 \mathrm{ng} / \mathrm{ml}$. Slides were then treated as described by Coen et al. (1990) in accordance with manufacturer's instructions (Boehringer Mannheim) for detection and colour development. Bright field photographs were taken on an Axiophot Zeiss microscope with 400ASA Kodak Gold films.

\section{Histone H1 kinase assay}

Histone H1 kinase assay was performed as described by Sauter et al. (1995) with the following modifications: proteins were extracted by freezing and grinding carrot somatic embryos in liquid $\mathrm{N}_{2}$. The crude extract was centrifuged at $12000 \mathrm{rpm}$ for $30 \mathrm{~min}$ at $4^{\circ} \mathrm{C}$ and the supernatant utilized in kinase assays. Each sample $(0.2 \mu \mathrm{g}$ of protein) was incubated in the reaction mixture in the presence of $1.25 \mu \mathrm{Ci}\left[\gamma^{-32} \mathrm{P}\right]$ ATP $(3000 \mathrm{Ci}$ $\mathrm{mmol}^{-1}$ ), with or without histone H1. Sample was then analysed on $10 \%$ SDS-polyacrylamide gels followed by autoradiography. Protein concentration was determined according to Bradford (1976).

\section{RESULTS}

Spatial and temporal expression of top1 genes in auxin-stimulated carrot hypocotyls

When hypocotyls are explanted from carrot seedlings and cultivated in vitro in the presence of auxin $(2,4-\mathrm{D})$ in the medium, only provascular cells are stimulated to actively proliferate in response to the phytohormone exposure, whereas cells of the cortical parenchyma enlarge but do not contribute to the dividing population. Moreover, the contribution of wounding to this event can be excluded, since the same process was also induced in the entire carrot plantlets (Guzzo et al., 1994).

In order to study the relationship between top 1 gene expression and the induction of cell proliferation, we decided to utilize this experimental approach analysing the temporal and spatial accumulation of both topl transcripts in explanted hypocotyls by in situ RNA hybridization.

Preliminary data obtained by northern blot analysis had shown that the accumulation of topl transcripts reached the maximum level (8-fold the amount present at zero time) after $20 \mathrm{~d}$ from exposure (Balestrazzi et al., 1996). In this study, ${ }^{35} \mathrm{~S}$ - labeled sense and antisense riboprobes able to detect both topl $\alpha$ and $\beta$ mRNAs were in situ hybridized to hypocotyl sections after 1, 2, 4 and 7 $\mathrm{d}$ from the induction event. No signal above background was observed at zero time in the epidermis, cortical parenchyma, procambial cells and vascular elements (Fig. 1, B) and very little accumulation of the topl transcripts appeared to have occurred after $1 \mathrm{~d}$ (not shown). However, after $2 \mathrm{~d}$, hybridization signals were clearly detectable in close proximity of vascular elements where procambial tissue is localized (D). Transcript accumulation was far more evident after 4 (not shown) and $7 \mathrm{~d}$ from induction $(\mathrm{F}$ and $\mathrm{H})$. As evidenced by staining with Giemsa, the presence of proliferating cell masses was observed near the vascular tissue (E and G) and the accumulation of topl transcripts was clearly localized only in those regions ( $\mathrm{F}$ and $\mathrm{H})$. For each time, control sections, which were hybridized with the sense riboprobe, did not give any signal above the background (not shown).

These results show that the transcript accumulation is spatially restricted to provascular tissue, namely the only tissue of an explanted hypocotyl which proliferates in response to the presence of the synthetic auxin 2,4-D.

Expression of the top1 genes during somatic embryogenesis

Somatic embryogenesis represents a useful system for the dissection of molecular events that occur when the induction of cell proliferation is associated to a developmental program. The process is characterized by localized and rapid cell divisions and therefore we decided to gain some insight into the regulation of topl gene expression during carrot embryogenesis.

Somatic embryos were collected at 1,8 and $14 \mathrm{~d}$ after transfer of proembryogenic masses (PEMs), isolated from carrot suspension cultures, to fresh medium in the absence of auxin. It is worth noting that somatic embryos originate in vitro from these cell clusters (Halpering, 1966). To gain information on the proliferative state of the embryo populations, we decided to analyse the level of p34 $4^{\mathrm{cd} 2 / \mathrm{CDC} 28}$-like histone kinase activity in embryos collected at 1,8 and $14 \mathrm{~d}$ after induction. This protein kinase, which is required for entry into mitosis, represents an essential component of the regulatory machine of cell division in eukaryotic 

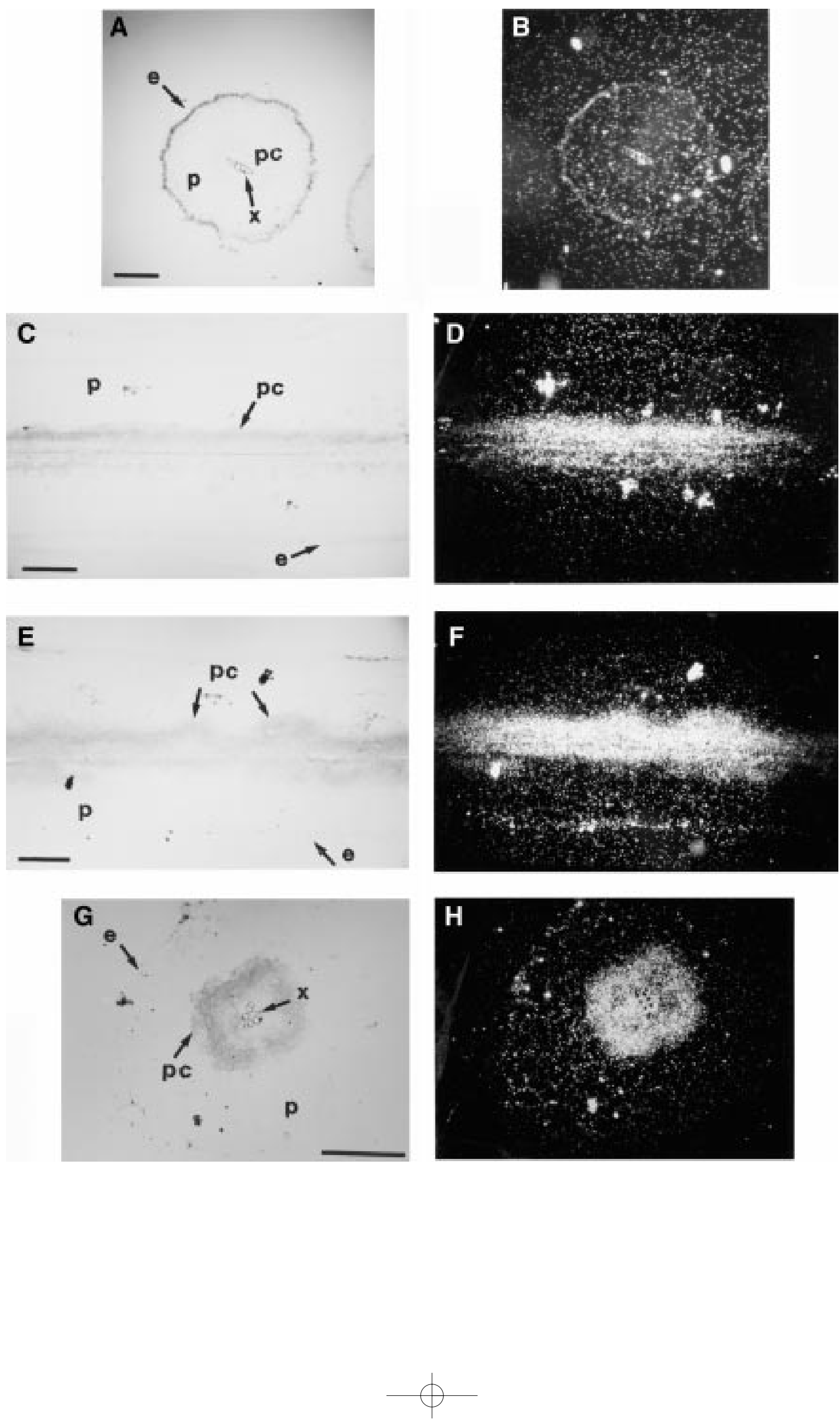


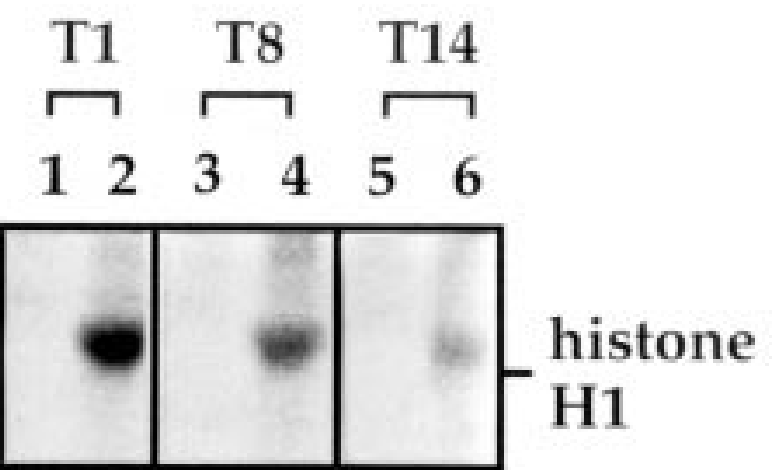

Fig. 2 - Histone H1 kinase activity during carrot somatic embryogenesis. Somatic embryos were collected $1\left(\mathrm{~T}_{1}\right), 8\left(\mathrm{~T}_{8}\right)$ and $14 \mathrm{~d}\left(\mathrm{~T}_{14}\right)$ after induction and crude extracts from each sample were prepared. An aliquot $(0.2 \mu \mathrm{g}$ of protein) from each extract was incubated in the reaction mixture containing $1.25 \mu \mathrm{Ci}\left[\gamma^{-32} \mathrm{P}\right]$ ATP, in the presence (lanes $\left.2,4,6\right)$ or in the absence (lanes 1, 3, 5) of histone H1 (20 $\mu \mathrm{g})$. The presence of $32 \mathrm{P}-$ labeled histone $\mathrm{H} 1$ was analysed by SDS-PAGE followed by autoradiography.

organisms (Gorst et al., 1991) As shown in Fig. 2, in vitro phosphorylation of histone H1, performed to assay the p34 protein kinase activity, peaked at the $T_{1}$ stage at the beginning of somatic embryogenesis (lane 2) and slightly decreased in $\mathrm{T}_{8}$ and $\mathrm{T}_{14}$ (lanes 4 and 6, respectively) populations. When exogenous histone $\mathrm{H} 1$ was omitted, no labeled protein was detected, thus demonstrating the specificity of the assay (lanes 1, 3, 5).

Information on the spatial distribution of the top1 transcripts were achieved by in situ RNA hybridization performed on somatic embryos using the same riboprobes detecting both $\alpha$ and $\beta$ transcripts previously described. Topl transcripts appeared to be distributed quite uniformly in early embryos (data not shown). In later embryo stages such as in late torpedos (Fig. 3, A), topl mRNAs were clearly located in root and shoot meristems, in cotyledons and in the provascular region, namely in tissues characterized by cell proliferation, but the localization was not strictly restricted to meris- tematic regions (Fig. 3, B). All tissue sections were also analysed with the sense top 1 riboprobe, but no signal above the background was in all cases detected (not shown).

Distribution of top $1 \alpha$ and $\beta$ transcripts in vegetative apices from carrot plantlets

Differently from previous experiments, the spatial localization of both topl $\alpha$ and $\beta$ transcripts was evaluated using gene-specific probes and in situ RNA hybridization was performed using a nonradioisotopic labeling system (digoxigeninlabeled probes), since this technique seems to offer the opportunity of detecting more precisely the expression pattern in single cells (Schmidt $e t$ al., 1996). Longitudinal sections of vegetative apices from 50-day-old carrot plants were used as starting material. In these experiments, sections were hybridized with antisense and sense RNA probes. Both topl $\alpha$ (Fig. 4, A) and $\beta$ (Fig. 4, B) mRNAs were evenly distributed within regions such as meristems and leaf primordia where active cell proliferation occurs. However, no significant differences between top $1 \alpha$ and top $1 \beta$ hybridization patterns were observed in these tissues. As expected, hybridizations with sense RNAs gave no specific labelling (data not shown). The uniformly distribution of both top $1 \alpha$ and top $1 \beta$ exactly reflected the spatial distribution observed when the same experiment was performed with the ubi-CEP (ubiquitin-carboxyl extension protein) probe (data not shown), a gene whose expression level was shown to be enhanced in rapidly dividing cells (Balestrazzi et al., 1998).

\section{DISCUSSION}

In mammalian cells the regulation of DNA topoisomerase I occurs at the transcriptional and posttranslational level throughout the cell cycle. Nevertheless opposite opinions on the relationship

Fig. 1 - Spatial and temporal expression of topl genes in carrot hypocotyl-cells induced to proliferate in 2,4-D-containing medium. Tissue sections were in situ hybridized with ${ }^{35}$ S-labeled antisense RNA probe derived from pTop28 and recognizing both topl $\alpha$ and $\beta$ transcripts. Sections were then stained with 5\% Giemsa. Bright- (A) and dark-field (B) photographs of a transverse section of hypocotyl at zero time. Bright- $(\mathbf{C}, \mathbf{E})$ and dark-field $(\mathbf{D}, \mathbf{F})$ photographs of longitudinal sections of hypocotyls after $2 \mathrm{~d}(\mathbf{C}, \mathbf{D})$ and after $7 \mathrm{~d}(\mathbf{E}, \mathbf{F})$ from the induction of proliferation. Bright- $(\mathbf{G})$ and dark-field (H) photographs of a transverse section of hypocotyl after $7 \mathrm{~d}$ from the induction.

e, epidermis, p, cortical parenchyma, pc, provascular cells and x, xylematic elements. Proliferating cell masses of provascular cells (pc) are showed by arrows. Bar, $100 \mu \mathrm{m}$. 

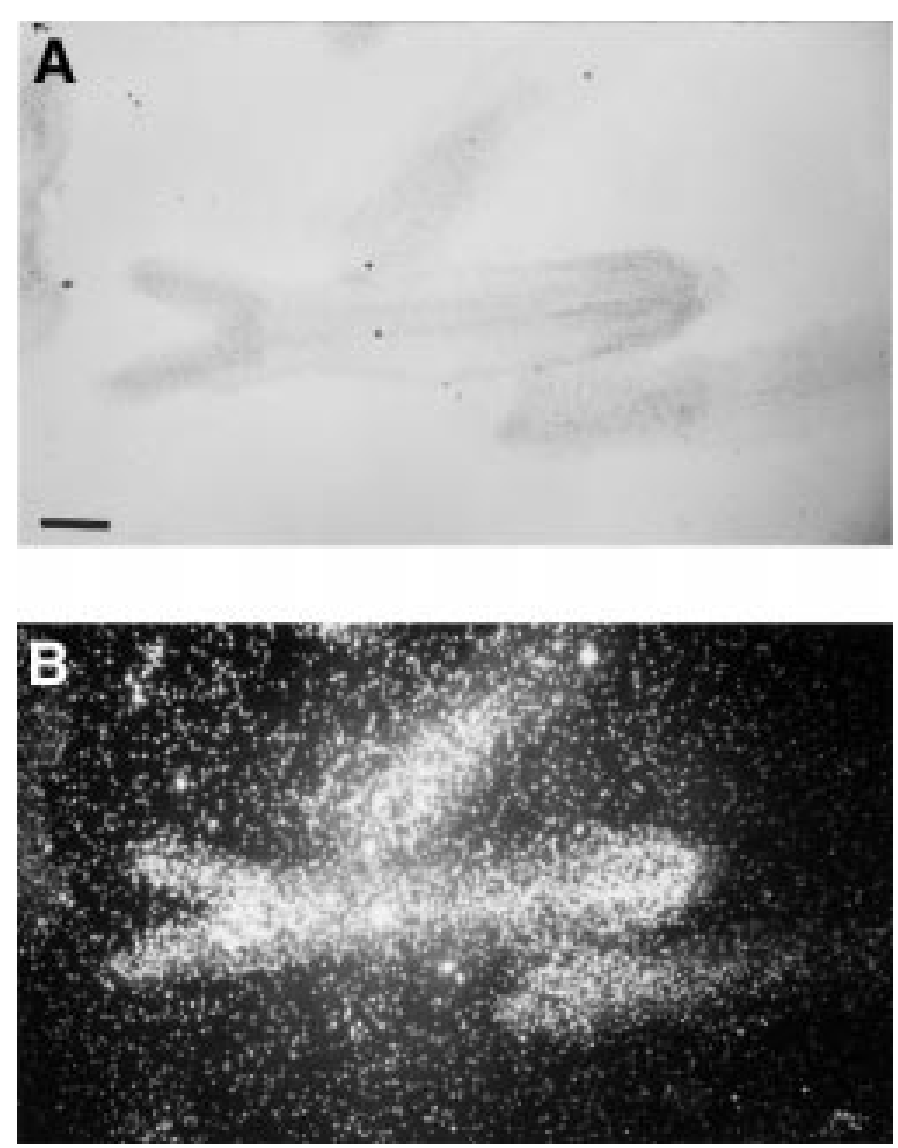

Fig. 3 - In situ localization of top1 mRNAs in 14 d-old somatic embryos. Tissues were hybridized as described in Fig. 1. Bright- (A) and dark-field (B) photographs of longitudinal sections of torpedo somatic embryos. Bar, $200 \mu \mathrm{m}$.

between topoisomerase I expression and cell proliferation have been expressed, over the past few years several data on the presence of topl transcript fluctuations during cell cycle have been reported (Kelly et al., 1983; Hwong et al., 1989; Romig and Richter, 1990a and 1990b). In particular, recent experiments suggested that the human topl gene is expressed just before the $\mathrm{G}_{1} / \mathrm{S}$ transition in $\mathrm{T}$ lymphocytes that are induced to enter cell cycle by PHA stimulation and that both mRNA and protein accumulations parallel DNA synthesis. In addition, human topoisomerase I is subjected to a degradation process during proliferation with the aim, as hypothized by authors, to maintain the enzyme at low level in the cell (Hwong et al., 1993).

In this study, we have examined the response of topl genes to events inducing proliferation in plant systems which, differently from cell suspension cultures, allow to obtain information on top1 transcript localization at the tissue level. Results of the in situ RNA analysis of the transcript distribution during hypocotyl-cell proliferation provide evidence that only procambium, induced to proliferate by the presence of 2,4-D in the medium, reveals an enhanced level of top1 transcripts. An additional information supplied by these experiments concerns the kinetics of topl accumulation in response to 2,4-D. We found that hybridization signals were only detectable after $24 \mathrm{~h}$, then excluding a direct effect of the synthetic phytohormone on topl gene induction, since the transcriptional activation of several auxin-induced genes has been described as a rapid event which frequently requires only minutes (Theologis, 1986).

Embryogenic cell cultures may be utilized to produce large amounts of somatic embryos by selecting, from the heterogeneous population, cell clusters named proembryogenic masses (PEMs) and transferring them to 2,4-D-free medium at a low density (Sung and Okimoto, 1983). Embryo development is generally described as a process characterized by a strong boost to cell division in early stages.

It has been reported that a reprogramming of gene expression occurs at the transition from globular to more mature embryo forms (Zimmerman, 1993). At that stage both division and differentiation events give rise to the tissues and organs of the future adult plant. Since topoisomerase I is directly involved in the regulation of transcription (Merino et al., 1993) and, in addition, is located in regions of active transcription (Fleischmann et al., 1984; Gilmour and Elgin, 1987), we can speculate that the spatial distribution of the topl mRNAs during somatic embryogenesis may be also related to a reprogramming of the expression of genes whose products are necessary in the organization of new tissues and then particularly at the heart-torpedo stages.

It is interesting to note that the carrot gene Met221 , encoding the enzyme DNA (cytosine-5)-methyl- 
Fig. 4 - In situ localization of topl $\alpha(\mathbf{A})$ and topl $\beta(\mathbf{B})$ transcripts in carrot shoot apices. Longitudinal sections of shoot apices from 50-d old carrot plants were hybridized with digoxigenin-labeled RNA probes generated by in vitro transcription of top $1 \alpha$ and top $1 \beta$ cDNAs, as outlined in Materials and Methods. A. Section hybridized with the topla antisense RNA probe. B. Section hybridized with the top $1 \beta$ antisense RNA probe. The bar equals 300 $\mu \mathrm{m}$.

transferase and having a maximal expression in proliferating cells, shows a transcript distribution mainly concentrated in apical and root meristems at the torpedo-stage (Bernacchia et al., 1998).

Finally, we investigated the spatial distribution of each topl transcripts by in situ hybridization of carrot vegetative apices, in order to verify the possibility that one of these genes could show a cell cycledependent expression pattern. Cell cycle-related genes are characterized by "spotty" expression patterns in apical meristems because their transcripts accumulate during specific phase(s) of the cell cycle and meristematic cells are not synchronized (Fobert et al., 1994). Both topl mRNAs appear to be uniformly distributed within tissues having an high rate of division, such as the meristem and the leaf primordium, confirming that topl gene expression and cell proliferation are strongly correlated. However, there is evidence neither for a periodicity of topl expression throughout the cell cycle nor for a spatial difference in their mode of expression.

\section{ACKNOWLEDGEMENTS}

This research was supported by research funds of a MURST PRIN (1999).

\section{REFERENCES}

Alsner J., Svejstrup J.Q., Kjeldsen E., Sorensen B.S., and Westergaard O.: Identification of a N-terminal domain of eukaryotic DNA topoisomerase I dispensable for catalytic activity but essential for in vivo function. J. Biol. Chem. 267, 12408-11, 1992.

Balestrazzi A., Carbonera D., and Cella R.: Transformation of Daucus carota hypocotyls mediated by Agrobacterium tumefaciens. J. Genet. \& Breed. 45, 135-140, 1991.

Balestrazzi A., Toscano I., Bernacchia G., Luo M, Otte S. and Carbonera D.: Cloning of a cDNA encoding DNA topoisomerase I in Daucus carota and expression analysis in relation to cell proliferation. Gene 183, 183-190, 1996.

Balestrazzi A., Cella R., and Carbonera D.: Cloning and expression analysis of a cDNA for carrot ubiquitin carboxyl extension protein (Accession $\mathrm{N}^{\circ}$ U68751). (PGR 98-109), Plant Physiol., 117, 720, 1998.

Balestrazzi A., Chini A., Bernacchia G., Bracci A., Luccarini G., Cella R., and Carbonera D.: Carrot cells contain two top1 genes having the coding capacity for two distinct DNA topoisomerases I. J. Exp. Bot. 51, 1-12, 2000.

Baker S.D., Wadkins R.M., Stewart C.F., Beck W.T., and Danks M.K.: Cell cycle analysis of amount and distribution of nuclear DNA topoisomerase I as determined by fluorescence digital imaging microscopy. Cytometry 19, 134-145, 1995.

Bernacchia G., Primo A., Giorgetti L., Pitto L., and Cella R.: 
Carrot DNA methyltransferase is encoded by two classes of genes with differing patterns of expression. The Plant J. 13, 317-329, 1998

Bradford M.M.: A rapid and sensitive method for the quantitation of microgram quantities of protein utilizing the principle of protein-dye binding. Analyt. Biochem. 72, 248-254, 1976.

Buckwalter C.A., Lin A.H., Tanizawa A., Pommier Y.G., Cheng Y.C., and Kaufman S.H.: RNA synthesis inhibitors alte the subnuclear distribution of DNA topoisomerase I. Cancer Res. 56, 1674-1681, 1996.

Coen E.S., Romero J.M., Doyle S., Elliot R., Murphy G., and Carpenter R.: Ifloricaula: a homeotic gene required for flowe development in Antirrhinum majus. Cell 63, 1311-1322, 1990.

deVries S.C., Booij H., Meyerink P., Huisman G., Dayton Wilde H., Thomas T.L., and van Kammen A.: Acquisition o embryogenic potential in carrot cell-suspension cultures Planta 176, 196-204, 1988.

Fleischmann G., Pflugfelder G., Steiner E.K., Javaherian K., Howard G.C., Wang J.C., and Elgin S.C.R.: Drosophila DNA topoisomerase $\mathrm{I}$ is associated with transcriptionally active regions of the genome. Proc. Natl. Acad. Sci. USA 81, 6958$6962,1984$.

Fobert P.R., Coen E.S., Murphy G.J.P., and Doonan J.H.: Patterns of cell division revealed by transcriptional regulation of genes during the cell cycle in plants. The EMBO J. 13, 616624, 1994.

Gilmour D.S., and Elgin S.C.R.: Localization of specific topoisomerase I interactions within the transcribed region of active heat shock genes by using the inhibitor camptothecin. Mol. Cell. Biol. 7, 141-148, 1987.

Giuliano G., Rosellini D., and Terzi M.: A new method for the purification of the different stages of carrot embryoids. Plant Cell Rep. 2, 216-218, 1983

Gorst J.R., John P.C.L., and Sek F.J.: Levels of p34 ${ }^{\mathrm{cdc} 2}-$ like protein in dividing, differentiating and dedifferentiating cells of carrot. Planta 185, 304-310, 1991.

Guzzo F., Baldan B., Mariani P., Lo Schiavo F., and Terzi M. Studies on the origin of totipotent cells in explants of Daucus carota L. J. Exp. Bot. 45, 1427-1432, 1994.

Kelly K., Cochran B.H., Stiles C.D., and Leder P.: Cell-specific regulation of the c-myc gene by lymphocyte mitogen and platelet-derived growth factor. Cell 35, 603-610, 1983.

Halpering W.: Alternative morphogenetic events in cell suspensions. Am. J. Bot. 53, 443-453, 1966

Hirt H., and Heberle-Bors E.: Cell cycle regulation in higher plants. Sem. Dev. Biol. 5, 147-154, 1994.

Hwong C.L., Chen M.S., and Hwang J.: Phorbol ester transiently increases topoisomerase I mRNA levels in human skin fibroblasts. J. Biol. Chem. 264, 14923-14926, 1989.

Hwong C.L., Chen M.S., Shang H-F, and Hwang J.: Increased synthesis and degradation of DNA topoisomerase I during the initial phase of human T lymphocyte proliferation. J. Biol. Chem. 268, 18982-18986, 1993

Merino A., Madden K.R., Lane W.S., Champoux J.J., and Reinberg D.: DNA topoisomerase I is involved in both repression and activation of transcription. Nature 365, 227-232, 1993

Meyer K.N., Kjeldsen E., Straub T., Knudsen B.R., Hickson I.D., Kikuchi A., Kreipe H., and Boege F.: Cell cycle-coupled relocation of types I and II topoisomerases and modulation of catalytic enzyme activities. J. Cell Biol. 136, 775-788, 1997.

Romig H., and Richter A.: Expression of the topoisomerase I gene in serum stimulated human fibroblasts. Biochem. Biophys. Acta 1048, 274-280, 1990a.

Romig H., and Richter A.: Expression of the type I DNA topoisomerase gene in adenovirus-5 infected human cells. Nucleic Acids Res. 18, 801-808, 1990 b.

Rossi F., Labourier E., Forné T., Divita G., Derancourt J., Riou J.F., Antoine E., Cathala G., Brunel C., and Tazi J.: Specific phosphorylation of SR proteins by mammalian DNA topoisomerase I. Nature 381, 80-2, 1996.

Sauter M., Mekhedov S.L., and Kende H.: Gibberellin promotes histone $\mathrm{H} 1$ kinase activity and the expression of cdc2 and cyclin genes during the induction of rapid growth in deepwater rice internodes. The Plant J. 7, 623-632, 1995.

Sekiguchi J., and Shuman S.: Site-specific riboniclease activi ty of eukaryotic DNA topoisomeraseI. Mol. Cell 1, 89-97, 1997.

Schmidt E.D.L., van Hengel A.J., and De Vries S.C.: A rapid method for localizing cell-specific transcipts in plant cell cultures. Biochemica, 4, 25-28, 1996.

Smith A.G., Hinchee M., and Horsch R.: Cell and tissue specific expression localized by in situ RNA hybridization in floral tissues. Plant Mol. Biol. Rep. 5, 237-241, 1987.

Steeves T.A., and Sussex I.M.: Development of the floral apex. In: Patterns in plant development, Ed 2 Cambridge University Press, Cambridge, pp. 179-189, 1989.

Sung Z.R., and Okimoto R.: Coordinate gene expression during somatic embryogenesis in carrots. Proc. Natl. Acad. Sci. USA 80, 2661-2665, 1983.

Theologis A.: Rapid gene regulation by auxin. Annu. Rev. Plant Physiol., 37, 407-438, 1986.

Wang J.C.: DNA topoisomerases. Annu. Rev. Biochem. 65 635-692, 1996

Zimmerman J.L.: Somatic embryogenesis: a model for early development in higher plants. The Plant Cell 5, 1411-1423, 1993. 